\title{
Surveillance of congenital cytomegalovirus in the UK and Ireland
}

\author{
Claire L Townsend, ${ }^{1}$ Catherine S Peckham, ${ }^{1}$ Pat A Tookey ${ }^{1}$
}

\begin{abstract}
${ }^{1}$ MRC Centre of Epidemiology for Child Health, UCL Institute of Child Health, University College London, London, UK
\end{abstract}

\section{Correspondence to} Dr Claire L Townsend MRC Centre of Epidemiology for Child Health, UCL Institute of Child Health, University College London, 30 Guilford Street, London WC1N 1EH, UK:

c.townsend@ich.ucl.ac.uk

Accepted 16 December 2010 Published Online First 2 February 2011

\begin{abstract}
Objective To explore the presentation and management of congenital cytomegalovirus (CMV) identified through routine clinical investigations, and ascertain outcome in early childhood.

Design Active population-based surveillance.

Setting UK and Ireland.

Methods Infants born in 2001-2002 with confirmed or suspected congenital CMV infection were reported through the British Paediatric Surveillance Unit, and clinicians completed questionnaires on presentation, diagnosis, management and subsequent outcome.
\end{abstract} Results 86 confirmed and 70 possible cases of congenital CMV infection were reported. Over a third (27/72) of singleton infants with confirmed and $44 \%$ (27/61) with possible congenital infection were preterm $(<37$ weeks gestation). Among confirmed cases, $75 \%$ (64/85) presented with neonatal manifestations compatible with congenital CMV, over half (34/64) of whom had neurological signs; 17 infants were treated with gancyclovir. Among confirmed cases with information on outcome, 31\% (24/78) were developing normally, $18 \%$ (14/78) had mild, 24\% (19/78) moderate and $14 \%(11 / 78)$ severe sequelae, and $13 \%(10 / 78)$ had died. Median age at follow-up among survivors was 18 months (IOR 15-22 months). Children with neonatal CMV manifestations were significantly more likely than those without to have moderate or severe outcomes (including death) $(60 \%, 36 / 60$, vs $22 \%, 4 / 18, p=0.001)$. $27 \%$ of survivors (17/63) had bilateral hearing loss. Conclusions The number of confirmed cases of diagnosed congenital CMV reported in this study was lower than expected, highlighting the need for early and appropriate investigations when congenital infection is suspected. Due to the unexpectedly high proportion of preterm infants, resulting from differential case ascertainment, it was difficult to distinguish prematurity and CMV-related symptoms.

\section{INTRODUCTION}

Cytomegalovirus (CMV) is the most common congenital infection worldwide. Seroprevalence of CMV in women of childbearing age in the UK is around $50 \%$, but varies by ethnicity, social class and parity. ${ }^{1}$ Congenital CMV infection can result from recurrent (reactivation of latent infection or reinfection with a new strain) or primary maternal infection in pregnancy. ${ }^{23}$ The birth prevalence of congenital CMV in resource-rich countries varies according to maternal seroprevalence, and in the UK is estimated to be around 3 per $1000 .{ }^{45}$ About $10-15 \%$ of congenitally infected infants are symptomatic at birth, ${ }^{6}$ and most of these experience serious long-term complications, such as cerebral palsy, cognitive impairment and sensorineural

\section{What is already known on this topic}

- Congenital cytomegalovirus (CMV) occurs in about 3 per 1000 births in the UK and is an important cause of deafness and disability in children.

- Most of the $10-15 \%$ of infected infants who are symptomatic develop long-term sequelae, as do some asymptomatic infants.

\section{What this study adds}

- Fewer children than expected were reported with congenital $\mathrm{CMV}$ in this population surveillance study, highlighting the difficulty of confirming congenital infection.

- An excess of preterm infants was reported, possibly due to opportunistic screening in some hospitals.

- Forty per cent of children reported with congenital CMV had moderate or severe outcomes, and $13 \%$ died.

hearing loss. ${ }^{6-8}$ In contrast, most asymptomatic infants develop normally, although a minority (10-15\%) develop long-term sequelae, sensorineural deafness being the most common problem. ${ }^{6}{ }^{9}$ There is some evidence that intravenous gancyclovir treatment may improve hearing outcomes in severely affected infants; ${ }^{10} 11$ however, due to concerns about toxicity, treatment is currently restricted to infants with central nervous system involvement. ${ }^{12}$

CMV is also commonly acquired in infancy, mainly through breastfeeding: in one UK study, $12 \%$ of infants born to CMV seropositive mothers acquired infection by 3 months, and $20 \%$ by 1 year. ${ }^{13}$ Although postnatal acquisition is usually asymptomatic in term infants, symptomatic infection can occur in very preterm infants. ${ }^{14}$ Congenital infection is conventionally distinguished from postnatal acquisition by virus isolation or DNA from urine or tissue samples collected in the first $2-3$ weeks of life..$^{15}$ For infants tested after this time, it is often not possible to distinguish between congenital and acquired infection, although testing stored neonatal dried blood spots can be helpful, with test sensitivity ranging from $71 \%$ to $100 \% .^{16}$

Surveillance of congenital CMV was carried out in the UK and Ireland, between 2001 and 2003, to ascertain the population prevalence of diagnosed 
congenital CMV disease, management strategies and clinical disease outcome. ${ }^{17}$

\section{METHODS \\ Data collection}

The study was carried out through the British Paediatric Surveillance Unit (BPSU) of the Royal College of Paediatrics and Child Health, an active monthly surveillance system for rare conditions of childhood. ${ }^{18} 19$ Paediatricians were asked to report all infants with confirmed or suspected congenital CMV infection born in the UK or Ireland in 2001 or 2002. Confirmed cases were infants with congenital CMV infection determined by PCR or virus isolation from urine, blood, saliva or tissue taken at biopsy within 3 weeks of birth; suspected cases were infants with symptoms compatible with congenital CMV infection aged under 12 months, with CMV isolated after 3 weeks of age. Since there was no national screening programme, it was not anticipated that asymptomatic infants or those with non-specific symptoms at birth would be reported. Paediatricians completed standard questionnaires on diagnosis, demographic and clinical factors, maternal details, treatment and outcome; at least two reminders were sent to non-responders. Follow-up information was requested during the second or third year of life to establish outcome. All diagnoses and investigations were undertaken locally as part of routine care.

\section{Case definition}

For this analysis, congenital CMV infection was defined as 'confirmed' based on a positive PCR, virus isolation or detection of early antigen fluorescent foci on a urine, blood, saliva or tissue sample taken at $<21$ days of age. ${ }^{6}$ Infants reported with only a positive IgM result during this period were classified as 'possible' cases, as were infants with earliest positive CMV results on samples taken at 21 days or later. Infants with laboratory evidence of postnatal CMV acquisition were excluded.

\section{Variables}

In this paper we describe infants as symptomatic if they had one or more of the following neonatal manifestations compatible with congenital CMV: ${ }^{6}$ hepatomegaly, splenomegaly, petechiae, thrombocytopenia, chorioretinitis, seizures, intracranial calcification or microcephaly (the latter four were also classified as neurological signs). The remaining infants are described as asymptomatic, even if they had other non-specific signs. Microcephaly and small for gestational age were based on age- and sex-specific z-scores derived from British 1990 population standards using the LMS method, ${ }^{20} 21$ and defined as an occipital-frontal circumference or birth weight below the third centile; where these measurements were missing, classification was based on clinical report. Subsequent outcome was categorised according to the presence and severity of reported sequelae, including hearing or visual impairment, seizures, motor or mental impairment or developmental delay. A summary measure of final outcome for surviving children was derived following review of all available information provided by clinicians, and classified by the researchers as normal, or mild, moderate or severe impairment (see table 1).

\section{Data management and statistical analysis}

Data were managed in Access 2003 (Microsoft, Redmond, Washington, USA) and analysed using Stata v 11 (StataCorp
LP, College Station, Texas, USA). Differences in proportions were compared using $\chi^{2}$ or Fisher's exact tests. The annual number of live births in England and Wales was obtained from Office for National Statistics data. ${ }^{22}$

\section{RESULTS}

Altogether, 224 paediatricians made 290 reports; 86 infants (born to 81 women) had confirmed congenital CMV, and 70 were possible cases. Fifty-eight infants were reported in error (most born outside the study period $(\mathrm{n}=31)$ or with postnatally acquired CMV infection). The remaining reports were duplicates $(n=55)$ or could not be assessed due to non-response $(\mathrm{n}=21)$. Reports of confirmed and possible cases came from all parts of the British Isles, with about a fifth from the London area, and over $60 \%$ from elsewhere in England (table 2). Seventy-two confirmed reports were from England and Wales (38 in 2001, 34 in 2002), giving an annual prevalence of 0.06 per 1000 live births (38/594 634 in 2001, 34/596 122 in $2002^{22}$ ).

\section{Maternal and infant characteristics}

Demographic characteristics were similar for confirmed and possible cases (table 2), apart from the proportion of twins: $15 \%$ of confirmed cases (including five twin pairs), and $7 \%$ of possible cases (no pairs) were twins. Median maternal age was 28 years (IOR 21-32 years for confirmed cases, $n=81$ mothers; IOR 23-33 years for possible cases, $n=64$ mothers). Among the confirmed singleton cases, 37\% (27/72) were preterm ( $<37$ weeks gestation), including $15 \%(11 / 72)$ born at $<32$ weeks; all 13 twins were preterm, with six born at $<32$ weeks (including two twin pairs). Among possible cases, 44\% (27/61) of singletons and all five twins were preterm; a third (21/61) of singletons and two twins were born at $<32$ weeks.

\section{Confirmed cases of congenital CMV Diagnosis and presentation}

Among infants with confirmed congenital CMV, the first available positive test was usually PCR or virus isolation; $88 \%$ were performed on urine samples (76/86), and 91\% (78/86) at $<7$ days of age (table 3 ).

Three quarters of infants had neonatal symptoms, over half with neurological involvement (table 3). Of 21 asymptomatic neonates, four had ultrasound abnormalities reported, and the mothers of seven had symptoms suggestive of CMV in pregnancy, including six with confirmed seroconversion. Other specific indications for neonatal testing were reported for

Table 1 Classification of infant outcome

\begin{tabular}{ll}
\hline Normal & No hearing problems or other impairments reported \\
Mild impairment & Unilateral hearing loss and/or other mild sequelae \\
Examples & Unilateral SNHL and mild speech delay \\
& Congenital heart defect repaired, mild delay \\
& Mild language/motor/developmental delay \\
Moderate impairment & Bilateral hearing loss and/or other moderate sequelae \\
Examples & Profound hearing loss \\
& Developmental delay and visual problems \\
Severe impairment & Poor vision, unilateral SNHL, mild developmental delay \\
Examples & Multiple disabilities \\
& Cerebral palsy, severe learning difficulties, bilateral SNHL \\
& Bilateral SNHL, global delay \\
& Quadriplegia, blindness, SNHL
\end{tabular}

SNHL, sensorineural hearing loss. 
Table 2 Demographic and perinatal characteristics of 86 infants ${ }^{*}$ with confirmed and 70 infants with possible congenital cytomegalovirus (CMV) infection born in 2001-2002

\begin{tabular}{|c|c|c|}
\hline & \multicolumn{2}{|l|}{ Congenital CMV } \\
\hline & Confirmed cases & Possible cases \\
\hline & n (\%) & n (\%) \\
\hline \multicolumn{3}{|l|}{ Region of birth } \\
\hline London & $18(21)$ & $16(23)$ \\
\hline England (excluding London) & $52(610)$ & $46(66)$ \\
\hline Scotland, Wales, Northern Ireland & $11(13)$ & $7(10)$ \\
\hline Ireland & $5(6)$ & $1(1)$ \\
\hline \multicolumn{3}{|l|}{ Twin } \\
\hline No & $73(85)$ & $65(93)$ \\
\hline Yes & $13(15)$ & $5(7)$ \\
\hline \multicolumn{3}{|l|}{ Sex } \\
\hline Female & $40(47)$ & $31(44)$ \\
\hline Male & $46(53)$ & $39(56)$ \\
\hline \multicolumn{3}{|l|}{ Ethnic group } \\
\hline White & $65(76)$ & $44(64)$ \\
\hline Black & $10(12)$ & $6(9)$ \\
\hline Other & $10(12)$ & $19(28)$ \\
\hline \multicolumn{3}{|l|}{ Parity (mother) } \\
\hline 0 & $48(56)$ & $38(55)$ \\
\hline 1 & $26(31)$ & $21(30)$ \\
\hline $2+$ & $11(13)$ & $10(14)$ \\
\hline \multicolumn{3}{|l|}{ Gestational age (completed weeks) } \\
\hline$\geq 37$ & $45(53)$ & $34(52)$ \\
\hline $35-36$ & $16(19)$ & $5(8)$ \\
\hline $32-34$ & $7(8)$ & $4(6)$ \\
\hline$<32$ & $17(20)$ & $23(35)$ \\
\hline
\end{tabular}

*Includes one infant with confirmed infection but minimal additional information.

eight additional infants without CMV symptoms or maternal indications (table 3). Ultrasound abnormalities or maternal symptoms were also reported for $27 \%$ (17/64) of symptomatic infants. In addition to signs classified as CMV compatible, many infants had other non-specific signs, for example, jaundice or anaemia. There were no statistically significant differences in neonatal presentation between term and preterm infants: $69 \%(31 / 45)$ of term infants were symptomatic, and $82 \%$ of preterm infants $(33 / 40, p=0.11) ; 42 \%(19 / 45)$ and $37 \%$ $(15 / 40)$, respectively, had neurological signs $(p=0.83)$.

Eight infants, all symptomatic, died within 8 weeks of birth; four had severe complications of prematurity and one a congenital syndrome (table 4). Four surviving infants had congenital abnormalities: cleft palate, positional talipes equinovarus, imperforate anus and cleft lip, and atrial septal defect.

\section{Gancyclovir treatment}

Seventeen infants with confirmed infection received intravenous gancyclovir, for a median duration of 6 weeks (range 4 days to 3 months); all but one had neonatal symptoms, including 11 with neurological signs (table 5). Treatment was discontinued for three infants due to neutropaenia (after 4 days), thrombocytopaenia (after 4 weeks) or abnormal liver function tests (after 5 weeks). Six infants with possible congenital CMV also received gancyclovir; all presented after 1 month of age with either bronchiolitis or pneumonitis.

\section{Outcome}

Follow-up information was provided for $89 \%$ (70/78) of children alive at first report. Two additional deaths were reported, both under 12 months of age (table 4); the median age of
Table 3 Indication for testing and neonatal presentation of 86 infants with confirmed congenital cytomegalovirus (CMV) infection born in 2001-2002

\begin{tabular}{|c|c|}
\hline & n (\%) \\
\hline \multicolumn{2}{|l|}{ Timing of primary CMV test (days of life) $(n=86)$} \\
\hline $0-2$ & $57(66)$ \\
\hline $3-6$ & $21(24)$ \\
\hline $7-13$ & $3(3)$ \\
\hline $14-20$ & $5(6)$ \\
\hline \multicolumn{2}{|l|}{ Type of primary CMV test $(\mathrm{n}=86)$} \\
\hline PCR & $31(36)$ \\
\hline Virus isolation & $31(36)$ \\
\hline DEAFF & $21(24)$ \\
\hline IgM (confirmed by PCR on neonatal dried blood spot) & $2(2)$ \\
\hline Histology & $1(1)$ \\
\hline \multicolumn{2}{|l|}{ Likely indication for CMV testing $(\mathrm{n}=85)$} \\
\hline Neonatal symptoms compatible with CMV (see below) & $64(75)$ \\
\hline Maternal/antenatal indication & $11(13)$ \\
\hline Other* & $8(9)$ \\
\hline No clear indication & $2(2)$ \\
\hline \multicolumn{2}{|l|}{ Neonatal symptoms and signs compatible with CMV $(\mathrm{n}=85)$} \\
\hline No & $21(25)$ \\
\hline Yes, without neurological signs & $30(35)$ \\
\hline Yes, with neurological signs & $34(40)$ \\
\hline \multicolumn{2}{|l|}{ Systemic $(n=85)$} \\
\hline Hepatomegaly & $36(42)$ \\
\hline Splenomegaly & $33(39)$ \\
\hline Petechiae, purpura & $37(44)$ \\
\hline Thrombocytopenia & $50(59)$ \\
\hline \multicolumn{2}{|l|}{ Visual $(n=79)$} \\
\hline Chorioretinitis & 1 (1) \\
\hline \multicolumn{2}{|l|}{ Neurological $(\mathrm{n}=85)$} \\
\hline Seizures & $3(4)$ \\
\hline Intracranial calcification & $16(19)$ \\
\hline Microcephaly $(<3$ rd percentile $) \dagger$ & $26(31)$ \\
\hline \multicolumn{2}{|l|}{ Small for gestational age $(<3$ rd percentile) $(n=85)$} \\
\hline No & $58(68)$ \\
\hline Yes & $27(32)$ \\
\hline
\end{tabular}

*0ther reasons included severe prematurity $(<32$ weeks, $n=2$, one with a symptomatic twin), other neonatal symptoms $(n=2)$, small head (although $\geq 3$ rd centile, $n=2)$ and HIV-infected mother $(n=2)$.

†16 infants were microcephalic and small for gestational age.

DEAFF, detection of early antigen fluorescent foci. The primary CMV test was the first available positive test.

surviving children when last seen was 17.7 months (IOR 14.921.8 months; range 4.2-33.9 months). Among 78 children with known outcome, 31\% (24/78) were developing normally, 18\% (14/78) had mild, 24\% (19/78) moderate and 14\% (11/78) severe sequelae, and $13 \%(10 / 78)$ had died. There were no significant differences in the proportion of children with moderate or worse outcomes according to gestational age: $52 \%(22 / 42)$ of term infants, $54 \%(12 / 22)$ of infants born at 32-36 weeks and $37 \%(6 / 16)$ of those born at $<32$ weeks had moderate or severe outcomes or died $(p=0.55)$. Symptomatic infants were significantly more likely than others to have moderate or worse outcomes $(60 \%$ vs $22 \%, p=0.001)$ and the rate was highest $(69 \%)$ if neurological signs were present neonatally (table 5). Among surviving infants, $79 \%(11 / 14)$ of those who received gancyclovir had moderate or severe impairment, as did 35\% (19/54) of those who did not $(p=0.006)$. Hearing problems were more common in children with neonatal symptoms (table $5)$, although this was not statistically significant $(p=0.09)$. Twenty-seven per cent of children had bilateral sensorineural 
Table 4 Details of 10 children with confirmed congenital cytomegalovirus (CMV) reported to have died

\begin{tabular}{|c|c|c|c|c|c|c|}
\hline Case & $\begin{array}{l}\text { Gestational } \\
\text { age (weeks) }\end{array}$ & Birth weight (g) & $\begin{array}{l}\text { Age at death } \\
\text { (weeks) }\end{array}$ & Treatment & Neurological signs & Additional details \\
\hline 1 & 27 & $<1000$ & $<1$ & No & IC & $\begin{array}{l}\text { Complications of } \\
\text { prematurity, hepatic } \\
\text { calcification }\end{array}$ \\
\hline 2 & 37 & $1500-2499$ & $<1$ & No & IC+microcephaly & Severe CMV symptoms \\
\hline 3 & 38 & $1000-1499$ & $<1$ & No & Ventriculomegaly & $\begin{array}{l}\text { Septicaemia, calcified } \\
\text { placenta }\end{array}$ \\
\hline 4 & 38 & $>2500$ & $<1$ & No & Microcephaly & $\begin{array}{l}\text { Erythroblastosis } \\
\text { fetalis, severe CMV } \\
\text { symptoms }\end{array}$ \\
\hline 5 & 29 & $<1000$ & $2-8$ & $<2$ weeks & IC+microcephaly+other & $\begin{array}{l}\text { Complications } \\
\text { of prematurity, } \\
\text { ventriculomegaly, } \\
\text { seizures }\end{array}$ \\
\hline 6 & 30 & $<1000$ & $2-8$ & No & Microcephaly & $\begin{array}{l}\text { Complications of } \\
\text { prematurity }\end{array}$ \\
\hline 7 & 35 & $1500-2499$ & $2-8$ & No & Seizures & Patau syndrome \\
\hline 8 & 39 & $1500-2499$ & $2-8$ & No & IC+microcephaly & $\begin{array}{l}\text { Multiple CMV } \\
\text { symptoms, bilateral } \\
\text { hearing loss }\end{array}$ \\
\hline $9^{*}$ & 24 & $<1000$ & $>8$ & 6 weeks & Microcephaly & $\begin{array}{l}\text { Pneumonia, chronic } \\
\text { lung disease, oedema, } \\
\text { complications of } \\
\text { prematurity }\end{array}$ \\
\hline $10^{*}$ & 34 & $1500-2499$ & $>8$ & 6 weeks & Ventriculomegaly & $\begin{array}{l}\text { Respiratory failure } \\
\text { (pneumonia) }\end{array}$ \\
\hline
\end{tabular}

*Death reported at follow-up.

IC, intracranial calcifications.

Table 5 Treatment and clinical outcome according to neonatal presentation

\begin{tabular}{|c|c|c|c|c|}
\hline & & \multicolumn{3}{|c|}{$\begin{array}{l}\text { Neonatal manifestations } \\
\text { compatible with congenital } \\
\text { cytomegalovirus }\end{array}$} \\
\hline & Total & No & $\begin{array}{l}\text { Yes, } \\
\text { non-neuro }\end{array}$ & $\begin{array}{l}\text { Yes, } \\
\text { neuro }\end{array}$ \\
\hline & n (\%) & $\mathbf{n}(\%)$ & n (\%) & $\mathrm{n}(\%)$ \\
\hline \multicolumn{5}{|l|}{ Treatment $(n=85)$} \\
\hline No & $68(80)$ & $20(95)$ & $25(83)$ & $23(68)$ \\
\hline Yes & $17(20)$ & $1(5)$ & $5(17)$ & $11(32)$ \\
\hline \multicolumn{5}{|l|}{ Summary outcome $(n=78)$} \\
\hline Normal & $24(31)$ & $13(72)$ & $6(21)$ & $5(16)$ \\
\hline Mild & $14(18)$ & $1(6)$ & $8(29)$ & $5(16)$ \\
\hline Moderate/severe/died & $40(51)$ & $4(22)$ & $14(50)$ & $22(69)$ \\
\hline \multicolumn{5}{|l|}{ Hearing $(n=63)^{*}$} \\
\hline Normal & $34(54)$ & $13(76)$ & $10(40)$ & $11(52)$ \\
\hline Unilateral/mixed hearing loss & $12(19)$ & $1(6)$ & $8(32)$ & $3(14)$ \\
\hline Bilateral sensorineural hearing loss & $17(27)$ & $3 \dagger(18)$ & $7(28)$ & $7(33)$ \\
\hline
\end{tabular}

*Excludes 10 children who died.

†All term infants, one small for gestational age, one borderline microcephalic (4th centile).

Neuro, neurological symptoms.

hearing loss (table 5), including four reported to have had cochlear implants.

\section{Possible congenital CMV}

Among 70 infants with possible congenital CMV, three had unconfirmed positive IgM results in the first 3 weeks of life. First available CMV test samples were taken at a median age of 65 days (range 0-264 days; IQR 35-107 days). A third $(24 / 70)$ of these infants had neonatal symptoms compatible with congenital CMV, over half $(13 / 24)$ of whom had neurological signs. Eleven infants died, at median age of 2.7 months (range 13 days to 9.5 months): nine were very preterm $(<32$ weeks, including six $<28$ weeks), one was reported as a sudden infant death and one died of respiratory and cardiac failure. Among surviving children with outcome information available, over half (32/56) were developing normally and $23 \%(13 / 56)$ had moderate or severe outcomes. Median age at follow-up was 20.4 months (IOR 11.4-28.1 months).

\section{DISCUSSION}

This observational surveillance study highlighted important issues relating to ascertainment of congenital CMV infection. We sought notification of infants with confirmed or suspected congenital CMV identified through routine investigations, and expected reports of infants presenting with manifestations of CMV disease. However, infants without typical CMV symptoms were also reported, and almost half of confirmed and suspected cases were preterm. In a similar Australian surveillance study, only $9 \%$ of reported infants were preterm ( $<36$ weeks), ${ }^{23}$ and congenital CMV is not an established risk factor for preterm birth. ${ }^{24}$ This excess of preterm infants could be due to differential case ascertainment arising from opportunistic screening policies; indeed, one respondent reported a local CMV screening policy for babies admitted to the special care unit. Case classification was particularly challenging, as in preterm infants it was difficult to differentiate symptoms compatible with CMV from those of prematurity. Furthermore, test results were sometimes inadequate and/or too late to distinguish congenital from postnatal infection. Symptomatic CMV disease following postnatal infection is more likely in low birthweight infants, ${ }^{14}$ and could have contributed to the high proportion of preterm infants among the possible cases. However, the natural history of early postnatal CMV acquisition remains poorly understood. ${ }^{25}$ 
This study was carried out through the BPSU, a well established active surveillance system, relying on clinical diagnosis through routine investigations. Overall, we identified 86 infants with confirmed congenital CMV born in 2001-2002, a reported prevalence of diagnosed congenital CMV 0.06 per 1000 live births) more than sixfold lower than expected if actual prevalence was 3 per 1000 births, ${ }^{4}$ with $10-15 \%$ symptomatic at birth. ${ }^{6}$ This low case ascertainment is probably due to the non-specific clinical presentation of congenital CMV, and the delay in taking appropriate samples early in life, as well as to under-reporting.

A further 70 infants suspected by clinicians of having congenital infection lacked confirmatory tests in the first 3 weeks of life and were classified as possible cases. This group is likely to have included both infants with congenital infection and those with early-acquired postnatal infection. Although TORCH screening (for toxoplasmosis, rubella, CMV and herpes simplex virus) has been discouraged over the last 20 years, ${ }^{26} 27$ this was specified in some reports with positive IgM, and results were not always followed up with appropriate and timely confirmatory tests. There is clearly a need for robust testing protocols when congenital CMV is suspected, ideally, viral culture or PCR on saliva or urine in the first $2-3$ weeks of life. ${ }^{12}$ Retrieval and testing of neonatal dried blood spots can also assist in the retrospective diagnosis of congenital CMV, but sensitivity can vary. ${ }^{1628-30}$ In an exercise reported elsewhere, only $75 \%$ of blood spots retrieved for confirmed cases in this study were positive. ${ }^{28}$

Almost half of the children in this study had serious disabling conditions or died, and almost a third of survivors had bilateral sensorineural hearing loss at a median follow-up age of 18 months. Despite study differences in definitions and case ascertainment, outcomes were similar to those reported elsewhere. For example, among children with neonatal symptoms, $32 \%$ had bilateral hearing loss, consistent with rates of $30-40 \%$ reported in the literature. ${ }^{31}$ Cases of late-onset hearing loss, which have been reported in other studies, ${ }^{32-34}$ could have been missed in this study due to the limited duration of follow-up. The proportion of symptomatic neonates with moderate or severe outcomes (about half) was comparable to the estimated $40-58 \%$ reported in a recent meta-analysis. ${ }^{8}$ However, we could not assess the extent to which neonatal manifestations or reported sequelae were affected by complications of prematurity or other underlying conditions. We were also unable to assess the effectiveness of gancyclovir treatment due to the lack of controls and selective use of treatment.

The children reported to this study were a subset of those born with congenital CMV in 2001 and 2002, and did not include those who were asymptomatic in infancy but developed late-onset sequelae. The true burden of disease associated with congenital CMV remains unknown. Nevertheless, the poor outcomes observed highlight the need for safe and effective treatment for congenitally infected infants. In light of recent advances in antiviral therapy for $\mathrm{CMV},{ }^{35}$ there is an urgent need to identify those children most likely to benefit from treatment in the future.

Acknowledgements The authors thank the British Paediatric Surveillance Unit (BPSU), supported by the Department of Health, for facilitating the data collection, and the reporting clinicians. The authors would also like to thank Dr Mike Sharland and Professor Marie-Louise Newell for their contributions to the design of this study, and Dr Kirsty Little for data collection. Any views expressed in this paper are those of the investigators and not necessarily those of the BPSU or the Department of Health.
Funding This work was undertaken at the Centre for Paediatric Epidemiology and Biostatistics, which benefits from funding support from the UK Medical Research Council (MRC) in its capacity as the MRC Centre of Epidemiology for Child Health. The UCL Institute of Child Health, University College London, receives a proportion of funding from the Department of Health's National Institute for Health Research Biomedical Research Centres funding scheme.

\section{Competing interests None.}

Ethics approval Ethics approval for this study was granted by the Great Ormond Street Hospital for Children NHS Trust/Institute of Child Health Ethics Committee.

Provenance and peer review Not commissioned; externally peer reviewed.

Contributors CT carried out the statistical analyses and drafted the paper. All authors contributed to the interpretation of the study, commented on all drafts of the paper and approved the final version.

\section{REFERENCES}

1. Tookey PA, Ades AE, Peckham CS. Cytomegalovirus prevalence in pregnant women: the influence of parity. Arch Dis Child 1992;67:779-83.

2. Gaytant MA, Steegers EA, Semmekrot BA, et al. Congenital cytomegalovirus infection: review of the epidemiology and outcome. Obstet Gynecol Surv 2002; 57:245-56.

3. Ahlfors K, Ivarsson SA, Harris S, et al. Congenital cytomegalovirus infection and disease in Sweden and the relative importance of primary and secondary maternal infections. Preliminary findings from a prospective study. Scand J Infect Dis 1984;16:129-37.

4. Peckham CS, Chin KS, Coleman JC, et al. Cytomegalovirus infection in pregnancy: preliminary findings from a prospective study. Lancet 1983;1:1352-5.

5. Griffiths PD, Baboonian C, Rutter D, et al. Congenital and maternal cytomegalovirus infections in a London population. Br J Obstet Gynaecol 1991;98:135-40.

6. Dollard SC, Grosse SD, Ross DS. New estimates of the prevalence of neurological and sensory sequelae and mortality associated with congenital cytomegalovirus infection. Rev Med Virol 2007;17:355-63.

7. Ahlfors K, Ivarsson SA, Harris S. Report on a long-term study of maternal and congenital cytomegalovirus infection in Sweden. Review of prospective studies available in the literature. Scand J Infect Dis 1999;31:443-57.

8. Ramsay ME, Miller E, Peckham CS. Outcome of confirmed symptomatic congenital cytomegalovirus infection. Arch Dis Child 1991;66:1068-9.

9. Kumar ML, Nankervis GA, Jacobs IB, et al. Congenital and postnatally acquired cytomegalovirus infections: Iong-term follow-up. J Pediatr 1984; 104:674-9.

10. Kimberlin DW, Lin CY, Sánchez PJ, et al. Effect of ganciclovir therapy on hearing in symptomatic congenital cytomegalovirus disease involving the central nervous system: a randomized, controlled trial. J Pediatr 2003;143:16-25.

11. Whitley RJ, Cloud G, Gruber W, et al. Ganciclovir treatment of symptomatic congenital cytomegalovirus infection: results of a phase II study. National Institute of Allergy and Infectious Diseases Collaborative Antiviral Study Group. $\mathrm{J}$ Infect Dis 1997;175:1080-6.

12. Ludwig A, Hengel H. Epidemiological impact and disease burden of congenital cytomegalovirus infection in Europe. Euro Surveill 2009;14:26-32.

13. Peckham CS, Johnson C, Ades A, et al. Early acquisition of cytomegalovirus infection. Arch Dis Child 1987;62:780-5.

14. Maschmann J, Hamprecht K, Dietz K, et al. Cytomegalovirus infection of extremely low-birth weight infants via breast milk. Clin Infect Dis 2001;33:1998-2003.

15. Grosse SD, Dollard S, Ross DS, et al. Newborn screening for congenital cytomegalovirus: options for hospital-based and public health programs. J Clin Virol 2009;46(Suppl 4):S32-6.

16. Barbi M, Binda S, Caroppo S. Diagnosis of congenital CMV infection via dried blood spots. Rev Med Virol 2006;16:385-92.

17. British Paediatric Surveillance Unit. 18th Annual Report, 2003-2004. London: Royal College of Paediatrics and Child Health, 2004. http://www.bpsu.inopsu.com (accessed 10 October 2010).

18. Lynn R, Ross E. The British Paediatric Surveillance Unit: the first 20 years. Arch Dis Child 2007;:92:744-5.

19. Lynn RM, Pebody R, Knowles R. Twenty years of active paediatric surveillance in the the UK and Republic of Ireland. Euro Surveill 2006;11:E060720.4.

20. Cole TJ, Freeman JV, Preece MA. British 1990 growth reference centiles for weight, height, body mass index and head circumference fitted by maximum penalized likelihood. Stat Med 1998;17:407-29.

21. Cole TJ, Green PJ. Smoothing reference centile curves: the LMS method and penalized likelihood. Stat Med 1992;11:1305-19.

22. Office for National Statistics. Birth Statistics: Review of the Registrar General on Births and Patterns of Family Building in England and Wales, 2005. London: HMSO, 2006. http://www.statistics.gov.uk/downloads/theme_population/ FM1_34/FM1_no34_2005.pdf (accessed 10 October 2010). 
23. Munro SC, Trincado D, Hall B, et al. Symptomatic infant characteristics of congenital cytomegalovirus disease in Australia. J Paediatr Child Health 2005:41:449-52.

24. Yamamoto AY, Mussi-Pinhata MM, Cristina P, et al. Congenital cytomegalovirus infection in preterm and full-term newborn infants from a population with a high seroprevalence rate. Pediatr Infect Dis J 2001;20:188-92.

25. Luck S, Sharland M. Postnatal cytomegalovirus: innocent bystander or hidden problem? Arch Dis Child Fetal Neonatal Ed 2009;94:F58-64.

26. Greenough A. The TORCH screen and intrauterine infections. Arch Dis Child Fetal Neonatal Ed 1994;70:F163-5.

27. TORCH syndrome and TORCH screening. Lancet 1990;335:1559-61.

28. Atkinson C. Walter S, Sharland M, et al. Use of stored dried blood spots for retrospective diagnosis of congenital CMV. J Med Virol 2009;81:1394-8.

29. Soetens 0, Vauloup-Fellous C, Foulon I, et al. Evaluation of different cytomegalovirus (CMV) DNA PCR protocols for analysis of dried blood spots from consecutive cases of neonates with congenital CMV infections. J Clin Microbiol 2008;46:943-6.
30. Barbi M, Binda S, Primache V, et al. Cytomegalovirus DNA detection in Guthrie cards: a powerful tool for diagnosing congenital infection. J Clin Virol 2000;17:159-65.

31. Grosse SD, Ross DS, Dollard SC. Congenital cytomegalovirus (CMV) infection as a cause of permanent bilateral hearing loss: a quantitative assessment. J Clin Virol 2008;41:57-62

32. Foulon I, Naessens A, Foulon W, et al. A 10-year prospective study of sensorineural hearing loss in children with congenital cytomegalovirus infection. J Pediatr 2008;153:84-8.

33. Fowler KB, Boppana SB. Congenital cytomegalovirus (CMV) infection and hearing deficit. J Clin Virol 2006;35:226-31.

34. Williamson WD, Demmler GJ, Percy AK, et al. Progressive hearing loss in infants with asymptomatic congenital cytomegalovirus infection. Pediatrics 1992;90:862-6.

35. Adler SP, Nigro G, Pereira L. Recent advances in the prevention and treatment of congenital cytomegalovirus infections. Semin Perinatol 2007;31:10-18. 


\title{
Surveillance of congenital cytomegalovirus in the UK and Ireland
}

\author{
Claire L Townsend, Catherine S Peckham and Pat A Tookey
}

Arch Dis Child Fetal Neonatal Ed 2011 96: F398-F403 originally

published online February 2, 2011

doi: 10.1136/adc.2010.199901

Updated information and services can be found at:

http://fn.bmj.com/content/96/6/F398.full.html

These include:

References This article cites 32 articles, 10 of which can be accessed free at: http://fn.bmj.com/content/96/6/F398.full.html\#ref-list-1

Email alerting Receive free email alerts when new articles cite this article. Sign up in service the box at the top right corner of the online article.

Notes

To request permissions go to:

http://group.bmj.com/group/rights-licensing/permissions

To order reprints go to:

http://journals.bmj.com/cgi/reprintform

To subscribe to BMJ go to:

http://group.bmj.com/subscribe/ 